\title{
AN EVALUATIVE STUDY OF AN ICT MODULE FOR A SCHOOL LEADERSHIP AND MANAGEMENT PREPARATION PROGRAM
}

\author{
Sarietjie MUSGRAVE \\ Open-Distance Learning \\ University of the Free State \\ Bloemfontein, South Africa
}

\author{
Corene DE WET \\ Open-Distance Learning \\ University of the Free State \\ Bloemfontein, South Africa
}

\section{ABSTRACT}

This study reports on findings of an evaluative study on the effectiveness of an information and communication technology (ICT) module that forms part of the Advanced Certificate in Education: School Leadership and Management program. The study was carried out among distance education (DE) students from the University of the Free State enrolled for above mentioned module. Two ICT audit surveys were used to gather data. This study used two modes of evaluation: Jung and Latchem's (2007) quality indicators for DE and comparison. The findings highlight ready access to ICT, technical support, appropriate guidance and support by knowledgeable, innovative and committed facilitators and the creation of a sense of community as imperatives for teaching education leaders ICT skills and knowledge.

Keywords: Distance education, ICT, ICT audit survey, quality assurance, South Africa, school leadership.

\section{INTRODUCTION}

The school principal is fundamental to the improvement of the quality of education and is seen as the gatekeeper of innovation and change (Bush, 2012). The principal often decides the fate of innovation that stems from the department or educators. This implies that school leaders should be prepared effectively to create good schools that will embrace innovation for the betterment of their schools. Information and communication technology (ICT) has the potential to improve the quality of education and training (Naicker, 2013). Researchers (Flanagan \& Jacobsen, 2003; Naicker, 2013) however, found that principals have not been prepared to assume the role of ICT leaders at their schools and have therefore struggled to develop both the human and technical resources necessary to achieve ICT outcomes in their schools. There is, nevertheless, no guarantee that school leadership preparation programs that include a section or module on ICT, will prepare principals to be effective ICT leaders. The effectiveness of leadership preparation programs, including ICT preparation programs, depend on the appropriateness thereof (Flanagan \& Jacobsen, 2003).

Bialobrzeska and Cohen (2005) developed a module (Managing ICTs in South African schools: A guide for school principals) to prepare current and aspiring education leaders in South Africa for their role as ICT leaders. This module forms an integral part of the Advanced Certificate in Education: School Leadership and Management (ACE:SLM) 
program. The ACE:SLM is offered as a distance education (DE), part-time program that makes provision for face-to-face meetings with facilitators. To meet the needs of ACE:SLM students in South Africa who are often geographically scattered in rural areas, face-to-face contact sessions are organized for these students at various centers around the country. The University of the Free State (UFS), Bloemfontein, South Africa, has been contracted by the Free State and Mpumalanga's provincial departments of education to present the ACE:SLM in their respective provinces.

While there are numerous definitions of DE, we follow Keegan's (1990) definition (cf. Simonson, Smaldino, Albright \& Zvacek, 2012 for a review of definitions). Keegan's (1990) definition identifies five main elements of DE: the separation of teacher and learner; the influence of an educational organization; the use of technical media to unite the teacher and learner and to carry educational content; the provision of two-way communication so that the student may benefit from or even initiate dialogue; and the possibility of face-to-face meetings with the teacher. The DE program under study includes these five elements. DE as a mode of delivery can help to overcome challenges of access, equity, cost effectiveness and quality for higher education in poverty stricken, remote rural areas (DHET, 2012; Wright, Dhanarajan \& Reju, 2009).

Quality assurance is important for the UFS. UFS have to compete with local and overseas institutions for the opportunity to present ACE:SLM and should also adhere to the criteria of the Higher Education Quality Committee (HEQC) of the South African Council of Higher Education (CHE, 2005). The South African Department of Higher Education and Training (DHET, 2012) places the responsibility for quality assurance first and foremost on the providers of DE. Quality in DE can be defined and judged as conforming to the standards applying to conventional education, fitness for purpose, meeting customers' needs, continuous improvement and conformity with international standards and requirements (Jung \& Latchem, 2007).

The coordinator and facilitator of the ICT-module - who is also the first author of this paper - made it clear from the outset that she did not want to use a linear instructional model when integrating ICT into her teaching of the ICT-module, but to use a more personalized, learner-centered, non-linear and learner-directed model (cf. Kundi \& Nawaz, 2010). In contrast to traditional lecture halls where lecturers use a linear model, the facilitator thus opted for a model that consists of three key components, namely: pedagogy, social interaction and technology (Wang, 2008). The theoretical foundations for this model can be found in social constructivism. This theory suggests that learners actively and collaboratively construct meaningful knowledge (Wang, 2008).

A pedagogical design that creates opportunities for active and collaborative ICT learning necessitates insight into learners' knowledge of ICT, as well as the reasons for their inadequate or proficient use of ICT. Insight into learners' differentiated prior knowledge of ICT is also an effective way to scaffold learners during the learning process. At the commencement of the ICT module, students were therefore asked to complete an ICT skills audit questionnaire. The aim of the ICT skills audit questionnaire is, among other things, to give insight into students' (who are also fulltime educators, see Table 1) proficiency to use ICT; their concerns regarding the ICT module; to form an important point of departure for the evolvement of the ICT module for ACE:SLM; and to form a point of reference for evaluating the quality of the ICT module. At the conclusion of the module - which has been presented as a DE part-time course over a period of two years - the students were once again asked to complete an ICT skills audit questionnaire. The central aim of the second questionnaire is the students' appraisal of the module by gaining insight in students' newly acquired ICT skills and their perceived value for them.

Using data emanating from both questionnaires the aim of this paper is to answer the following question: How effective is the ACE:SLM ICT DE module for education leaders and potential leaders? 


\section{CONTEXTUALISATION}

The ACE:SLM was introduced in South Africa during 2007 as a threshold qualification for aspiring school principals as part of the Department of Basic Education's (DBE) strategy to improve educational standards. The ACE:SLM is being delivered by universities through a common framework agreed upon with the national DBE and the National Management and Leadership Committee. The two-year, part-time qualification is presented at numerous canters around the country. School leaders, as well as potential leaders are annually invited by the nine provincial Departments of Education to apply to study for the ACE:SLM qualification. Successful applicants receive grants to cover all costs (including travelling costs).

This study was undertaken among 40 educators who were enrolled for the ACE:SLM, presented by the UFS in Ermelo, a small town in the poverty stricken Mpumalanga Province (MP) at the beginning of 2013. This cohort of students was presented with laptops which were bought by the university through the Student Laptop initiative and funding was provided by the MP Department of Education. Table 1 gives a summary of the demographic details of the 34 educators (hereafter referred to as participants) who completed both questionnaires.

Table 1. Demographic details of participants who completed both ICT audit survey $(n=34)$

\begin{tabular}{lll}
\hline Post level & Response percent & Response count \\
\hline Principal (P) & 38.2 & 13 \\
Deputy principal (DP) & 14.7 & 5 \\
Head of Department (HOD) & 38.2 & 13 \\
Post level 1 teacher (T) & 5.9 & 2 \\
District supervisor (DS) & 2.9 & 1 \\
\hline Type of school & Response percent & Response count \\
\hline Primary (Grade 1-7) & 41.2 & 14 \\
Secondary (Grade 8-12) & 35.3 & 12 \\
Combined (Grade 1-12) & 17.6 & 6 \\
Intermediate (Grade 1-9) & 2.9 & 1 \\
No response & $2.9 \%$ & 1 \\
\hline
\end{tabular}

The purpose of the ACE:SLM ICT module is to give school principals and senior management information on the use and management of ICT resources so that they can provide ICT leadership at their respective schools, and gain insights into the potential and implication of ICT usage for teaching and learning (Bialobrzeska \& Cohen, 2005).

Working within a non-linear, social constructivist framework the facilitator created opportunities for the students to actively and collaboratively construct meaningful knowledge (Wang, 2008). The following is a glimpse at the way the facilitator introduced the students into the world of ICT during the first workshop: to create a feeling of empowerment and ownership students were guided on how to set up their own computers - a task usually performed by technicians. Their first assignment was to use the Paint-program to portray what they thought to be the reasons why they were appointed to their specific promotion posts and to give their vision for their schools. Without their realizing, the students were taught how to use a mouse, type and save information on a computer. These pictures were used to introduce the students to one another. During the presentation of the pictures, students shared with one another how they used the Paint-program. The first ICT audit questionnaire, that was completed online during the first workshop gave the facilitator immediate feedback on the students' access to ICT. The survey showed, among other things, that $50 \%$ of them had access to computers at the school where they teach; $52.5 \%$ have a computer at home; and only $15 \%$ have access to the internet at the school where they teach. All the students 
indicated that they have their own mobile phones. Yet their responses on questions regarding their usage of MixIt and WhatsApp show that they do not use the mobile phones' applications optimally. Students were therefore guided on how to create 'buddy groups', a potentially important support basis for DE students, on their mobile phones. Office 365 accounts with email were created for all students. Through hands-on activities students were also guided as to how to send emails and attach files, and how to send instant messages to each other using their outlook accounts. Despite efforts by the facilitator to guide the students in the use of ICT, some of them were extremely anxious at the conclusion of the first workshop - as will emerge in our discussion of their concerns.

Over a period of two years, four full-day workshops were presented in Ermelo. Three fullday workshops were also presented at the Bloemfontein campus of the UFS. The latter was presented during school holidays and aimed to give the students the opportunity to work in an environment where there was adequate, high speed Wi-Fi internet access. The visit to the UFS was also important as it was possible for a technician to be available to support students with issues, such as viruses on their laptops, forgotten passwords, or hardware-related issues they might experience after using the computer for one year.

The facilitator and students corresponded by means of WhatsApp, text messages and mobile phones - a mobile phone was staffed by either the facilitator or her assistant during office hours. The turnaround time for enquiries was usually four hours. The facilitator also used an online OneNote document to attend to the most common concerns of the students.

As there was not reliable internet access in the areas where most of the students lived, the decision was made not to use an online learning management system (LMS), but rather to create the ACE:SLM course with all its modules in OneNote. This allowed for offline usage, as well as for online sharing and communication. OneNote was introduced during the first ICT workshop as a program that could be used to take notes in class. When students were shown how to use it offline, they easily adapted to the online version where they could collaborate on documents. This was enforced during the second workshop. Within two contact sessions, students started using their laptops for notetaking in other ACE:SLM modules as well. Students were also encouraged to utilize free Wi-Fi available in eateries in the larger towns and if available at their schools. Some of the students who reside in areas that have internet connectivity, later on entered into contracts with $3 G$ service providers.

\section{RESEARCH METHOD}

This study utilizes data originating from two ICT skills audit questionnaires developed by the first author. After an extensive study of the literature on educators' ICT competency levels (cf. Bialobrzeska \& Cohen, 2005; Bush, Duku, Glover, Kiggundu, Kola, Msila \& Moorosi, 2009), a pilot study conducted on the previous year's ACE:SLM students, and personal reflection (the first author has acted as facilitator for ICT modules at the UFS for 5 years), the ICT skills audit questionnaires were given to two colleagues, an educationalist and an ICT-expert, for further scrutiny. They were asked to establish the face and content validity of the questionnaires. Feedback from the two was used to ensure that the items measured the content areas of investigation and were culturally and technically appropriate for the context of the study (cf. Afshari, Bakar, Luan, Samah \& Fooi, 2009). The instruments included closed questions classified in predefined categories (demographic information; access to ICT; confidence level of ICT usage, including hardware and file organization, application software, audio and visual media, email, internet and social networking; ICT usage at the participant's school), as well as openended questions. The first questionnaire, completed during the first workshop, probed participants' ICT confidence levels before the onset of the module, aiming to ascertain their ICT proficiency, expectations and concerns regarding the ICT module. The second 
questionnaire, completed during the final workshop, investigated participants' ICT proficiency at the conclusion of the module, and their appraisal of the module.

In line with the aim of this paper, namely to investigate ACE:SLM students' appraisal of the ICT module, we will focus on data emanating from two open-ended items put to them during the first and last workshops respectively: What is your biggest concern/s for this year, regarding the module about ICT for school leaders? and Reflecting back on this module, what have you gained?

Content analysis was used to identify and summarize the content of the open-ended questions. Nieuwenhuis's (2007) guidelines for qualitative content analysis were used in order to reduce, condense and group the content of the answers to the open-ended questions. The two researchers analyzed the data independently. Thereafter, a consensus discussion was held to confirm the findings and enhance the trustworthiness of the study (Creswell, 2008).

\section{FINDINGS}

In the ensuing discussion of the findings emanating from the participants' answers to the open-ended questions, participant identifiers were used. Numbers were allocated to all participants at the completion of the first survey, whether or not they answered the openended questions (1-40). The following codes were used to identify the post levels of the participants: principal (P), deputy principal (DP), district supervisor (DS), head of department (HOD) and post level 1 teacher (T). 'Educator' is used as an umbrella term.

\section{Concerns Regarding the ICT Module}

Twenty of the 34 participants $(\mathbf{5 8 . 8 \%})$ who completed both surveys, provided answers to the following open-ended question put to them in the first ICT audit survey: What is your biggest concern/s for this year, regarding the module about ICT for school leaders?

Eight of the 20 participants who wrote about their concerns mentioned that they are apprehensive about using a computer. Four of them mentioned that they have never used a computer previously. The fact that they were informed during the first workshop that they would have to use a computer to complete their assignments and submit them electronically, was found to be daunting to several of them, e.g., "My concern is that I never used the computer before and it seems that I am expected to excel in using computer and I don't know whether I will master the basic skills so that I can communicate with the University and write my assignment using it" (11DP) and "My greatest concern is if I will be able to finish my assignments on time because I am struggling to type since it is my first time to operate a computer" (17HOD). Lack of typing skills, as alluded to by the above quoted participant, seems to be a common stumbling block for the participants. Several of the particpants also noted that they do not know how to send emails, do electronic searches on the internet and use the different Microsoft programmes.

Interlinked with partcipants' lack of ICT skills was their fear of failure, e.g., "Will I be able to properly use the computer when I am alone at home/school to complete my assignments? Will I remember all the steps that I have to follow when doing a particular exercise with the computer? Can I successfully complete all assignments of the course as expected? I want to pass this course" (22P). Four particpants expressed fear that they would not be able to cope with the demands of the ACE:SLM in general and the ICT module in particular, amidst their already heavy workload as education leaders.

During the first workshop the particpants were told that it would be expected of them to teach their colleages basic computer skills (an expected outcome of the module, cf. Bialobrzeska and Cohen, 2005). Given the fact that at that stage of their studies most of them had very basic or no ICT skills, it is understandable that they were concerned, e.g., 
"Will I be able to give or teach others the knowledge I will receive from training?" (15HOD) and "Will I be able to assist my colleagues with knowledge that I acquire?" (31P).

Only two of the particpants were not concerned about the ICT module, but saw it as an ideal opportunity to expand their existing ICT skills. One of them wrote: "I am eargerly looking forward to acquire more skills/knowledge in the usage of computers for school administration and curriculum implementation and its management" (16P).

Participants' concerns thus focused on the demands regarding the module, such as the requirements that assignments must be computer generated and electronically submitted, the ability to use specific Microsoft programs, the need to use electronic media to communicate with the facilitator, to search for information on the internet and to teach colleagues ICT skills. Participants moreover feared being left struggling without support and with the possibility of failure. The participants suggested that the possibility of failure was ever present due to their heavy workload, possible lack of support and their dearth of computer and software knowledge and skills. Participants' concerns and fears formed an important point of departure for the evolvement of the module. By means of electronic and telephonic communication with the students and during further workshops the facilitator tried to address students' concerns.

Reflective Assessment of ICT Module

Whereas the participants' answers to the question about their concerns attested to their fears and uncertainties, the following exposition of their reflections at the conclusion of the ICT module bear witness to their self-confidence, pride in acquiring ICT skills and praise for their facilitator.

A large percentage $(82.4 \%)$ of the participants who completed both questionnaires responded to the following request put to them in the second survey: Reflecting back on this module, what have you gained? Reflection, as defined by Dewey (1933) is a systematic, rigorous, disciplined way of thinking with its roots in scientific inquiry. Reflection is a part of the critical thinking process referring specifically to the processes of analyzing and making judgments about what has happened. Reflection, as Dewey defines it, cannot be equated with mere haphazard "mulling over" something (Rodgers, 2002: 849). By actively participating in reflective thinking - assessing what they knew, what they needed to know to become ICT proficient, and how they bridged that gap during learning situations - the participants gave us insight into what they had gained in the ICT module. In the ensuing discussion their reflections will, where possible, be presented against the background of the concerns expressed by them at the commencement of the ICT module.

A fear of failure was an important concern among participants at the commencement of their studies. An analysis of their reflections reveals that their fear was replaced by confidence. Several of the participants mentioned that the ICT module enhanced their confidence as leaders, e.g., "I am a confident manager because of the ICT skills" (1P) and "I gained confidence and self-esteem as a pioneer at my school" (11DP). Three of the participants moreover suggested that the acquisition of ICT skills made them better leaders, e.g., "All that I have learnt has made me a better leader and manager" (7P) and "I am a better manager as my administration skills have vastly improved" (28HOD). Not only did their professional confidence grow, but also their status among colleages, e.g., "I now command respect from my colleagues because I am always of assistance to them and I fit in the leadership descriptors" (7P) and "I gained a lot of respect from my colleagues" (5P). The confidence gained developed into a growth in selfworth, e.g., "I am proud that I can get on the internet to search for information with confidence" (2P) and "I can't believe that I am a member of a digital village" (17HOD).

The data furthermore revealed that some of the participants' growth in confidence and respect among colleagues within the school environment, transferred to a more vibrant 
leadership role in their communities, e.g., "I can prepare slides for presentations in meetings locally and outside the school" (1P).

Several of the participants acknowledged that they were dependent on their administrative staff for most, if not all computer-related work before they registered for the module. Four of them mentioned that they are no longer dependent on their administrative staff, e.g., "I am no longer a burden to my administrators; I even help them when they experience problems" (1P).

Whereas the partipcants previously voiced concerns that they would not be able to cope with their workload as school leaders and as students, some of them conceded, after completion of the module, that their newfound knowledge reduced their workload, e.g., "My workload has been extremely reduced ..." (17HOD) and ensured a more organised working environment, e.g., "I am more professional in keeping records" (37HOD).

While the particpants were anxious at the beginning of the module of the prospect of training their colleages in ICT skills, it seems from their reflections that there is an eagerness among some of them to share their newfound knowledge with members of staff, e.g., "I am ... determined to assist my staff members to bridge the digital divide" (17HOD) and I "teach my fellow educators computer skills" (16P).

The positive impact of the particpants' newly aquired ICT skills on their teaching and learning is highlighted by several of them, e.g., "My class is no longer the same because they write typed tests, get hand-outs extracted from the internet" (1P); "I use my skill to engage learners on the programmes of the Department of Education like downloading and answering old ANA (Annual National Assessment) papers" (12HOD) and "My learners seem to be enjoying my lesson presentations and their performance indicate a steady improvement" (28HOD). Participants thus use the internet to expand their own knowledge base of the subjects they teach, use technology to make their classes more interesting and learner centered, and guide their learners to gain ICT skills that may increase independent learning.

The study also found that the ICT module had a positive impact on particpants' personal lives. One of the principals wrote that "I now get my statements through email. When I want to buy something I just google and find out where to find it at what price. I have a grade 12 child. She has applied online for different institutions. I don't know how we would have done the applications if I didn't have ICT skills" (32P). Another principial noted that "Apart from emails, I can also communicate with friends and relatives through Facebook, WhatsApp and all these are benefits of the SLC 121 computer course" (34P). It was suggested by a principal that the ICT module had had a profound influence on his personal growth. Paying tribute to the facilitator, he wrote that she had taught him "perseverance, time management, how to be prepared before you get in front of learners, honesty, tolerance [and to be] knowledgeable" (16P).

A major concern that emerged while analyzing data from the first ICT audit was the participants' limited or nonexistent knowledge of computers per se, as well as computer software programs. In their reflections of what they have gained as students of the ICT module, participants also made reference to their initial lack of knowledge. Their reflections are an acknowledgement of how their skills have grown over time from being virtually nonexistent to being able to use ICT with confidence. The following two quotations aptly illustrate the participants' initial lack of knowledge: "I was a ZERO coming here" (28HOD) and "When Madam (referring to the facilitator) asked us to show her our ICT competency, I was at zero because I had never used a computer in my life. When I heard that we will have to write and submit assignments through computers via email, I wanted to give-up, but I told myself that failing to try won't help me" (32P). Thereafter he lists the skills he had acquired. Another school principal wrote: "When I started this course, I was really blank" (9P). He goes on to confess that "I am ashamed to mention the fact that for the first three months, I was travelling a distance to my friend 
who can email, as I was afraid to give my assignments to any Tom, Dick or Harry to email for me, but now I can do that even with my eyes closed" (9P).

In their reflective notes several of the particpants listed the computer programmes that they have mastered and the skills aquired. In numerous of the respondents' reflections it was also apparent that they were especially proud of the internet skills they had acquired. In the foregoing discussion we have already referred to the fact that participants now use the internet extensively to enhance their teaching.

Six of the participants paid tribute to the facilitator. All of them mentioned her by name. Reference was made to her "guidance, patience and hard work" (32P), her ability to motivate them, e.g., "All credit goes to ... who patiently opened my mind and eyes to see the importance of ICT" (17HOD), set new challenges to keep them interested, e.g., "Each time we were with you, there were always new things to learn" (7P), and motivated them to exceed their own expectations, e.g., "I have learnt more than what I thought I will" (32P). One of the participants wrote that "she will remain my mentor, my lifelong role model" (16P). (This paragraph should not be seen as self-glorification. It was included in this paper on the insistence of the second author. The aim of the inclusion is to illustrate the important role that facilitators play in the success or failure of teaching ICT competencies to adults, especially education leaders, in a DE program.)

While participants were in fear of failure at the start of the ICT module, their reflections attested to their satisfaction with acquiring ICT skills. Their reflections alluded to the positive impact of their newly acquired ICT skills on their multiple roles of teaching and learning, administrative and being community leaders. Being ICT literate contributed to their professional and personal growth. None of the participants offered any dissatisfaction with the content of the module, the mode of delivery or the facilitator.

\section{DISCUSSION}

Reliable, easy access to ICT by both learners and facilitators is a prerequisite for the successful delivery of any study that has an e-learning component (Harris, \& 2009). A common problem in teaching and learning ICT skills in South Africa is students' lack of ready access to ICT (Bialobrzeska \& Cohen, 2005). Only half of the educators who took part in this study had access to computers at the school where they teach and $52.5 \%$ had a computer at home when they enrolled for the ACE:SLM program. This cohort of students was, however, all presented with laptops during the first workshop. This addressed problems regarding ready access to computers. We acknowledge that this is an expensive solution to the problem of accessibility. Projects such as these have often been created with donor funding. Unfortunately, most are funded for specific periods of time. The DBE and the UFS with the support of donor organizations should thus prioritize the development of sustainable and affordable ICT projects to empower school leaders to become ICT leaders.

Reliable internet connectivity and electricity remain a challenge in rural areas of southern Africa (DHET, 2012; Wright et al., 2009). Ngugi (2011: 280) writes that "insufficient, unreliable and costly bandwidth makes a mockery of the notion of browsing the Internet for content and research". Wright et al. (2009) found that internet access in southern Africa can cost $\mathbf{2 0}$ to $\mathbf{4 0}$ times more than in northern America, as $\mathbf{8 0 \%}$ of the internet traffic is routed through satellites. According to the DHET (2012: 28) the minister of the DHET will put plans in action "within the foreseeable future ... to ensure ... meaning full access for all higher education students to appropriate learning technologies and broadband Internet access". Pending the realization of this promise, most of South African universities make use of mobile phone technology to communicate with their DE students (Aluko, 2009). To sidestep the lack of internet access in the remote rural areas where most of the MP students reside, the ACE:SLM course utilized OneNote rather than an online LMS. This enabled the students to seamlessly move from offline to online ICT. 
Students were also encouraged to use any available connectivity - be it their school's internet, entering into a 3G-contract or using free Wi-Fi at eateries.

Flanagan and Jacobson's (2003) finding that education leaders' lack of knowledge may impair their pedagogical vision and experience to guide members of their staff, was also evident in the concerns voiced by participants at the beginning of their studies. Appropriate ICT training, nonetheless allowed the participants to become ICT leaders in their schools. On the completion of the module, they were able to lead by example in their classes, through their use of ICT in fulfilling administrative functions and by teaching members of staff ICT skills. The importance of education leaders to take up the challenges presented by ICT and lead by example is highlighted in the literature (Hadijthoma-Garstka, 2011; Naicker, 2013). It is promising that some of the participants presented training to members of their staff. Naicker (2013) found that due to heavy workloads, South African educators rarely attend computer training courses - even if they are offered by the DBE. It should be noted that the ICT skills training of colleagues was an obligatory assessment task for the participants. The fact that they embraced the task and felt proud to share their newfound knowledge is heartening. It is however necessary to do follow-up studies to ascertain whether they will train new/other members of staff after the completion of their studies. Owing to the ever-changing ICT landscape, the training of educators should be an ongoing process.

Educators who completed the ICT module boasted of their innovative ICT-supported teaching and the benefits thereof for their leaners. The positive spinoffs of the integration of ICT into the learners' curriculum are supported by the literature (Mdlongwa, 2012; Naicker, 2013). Mdlongwa (2012: 3) notes, for example, that exposure to ICT allows learners to develop skills that will "give them an edge in an ever-increasingly technologysaturated work environment". The introduction of ICT moreover allows learners "to become creators of knowledge in their own right". Mdlongwa (2012) also writes that learners who use ICT for their assignments and projects begin to cultivate a culture of personal information management; independent learning and working without supervision; communication skills; teamwork; and research skills.

A finding of this study, namely that newfound ICT skills allow education leaders to use their time more effectively and to independently act as administrative leaders of their schools, is supported by research (Mdlongwa, 2012). This study highlights the positive impact of the ability to use technology to communicate. Using technology to communicate with colleagues, DBE, learners and parents creates effective, fast communication.

Researchers (Sikwibele \& Mungoo, 2009; Simonson et al., 2012) exposed the lack of adequate learner support as a fundamental problem faced by DE students. Botswana students told Sikwibele and Mungoo (2009: 4) that their tutors "failed" them and were "not helpful". Some of them went so far as to label their tutors as "lazy". These accusations and research findings stand in stark contrast to the homage paid to the facilitator of the ICT module under investigation. The important role a knowledgeable, committed facilitator in teaching adults' ICT skills - as highlighted by this study - is in line with prior research (Sampson, 2003; Simonson et al., 2012). Structures, such as an online OneNote document, as well as a helpline with a four-hour turnaround time, may have played an important role in the success of the ICT module.

To counter feelings of isolation, a common problem among DE students (Sampson, 2003), the facilitator guided the students during the first workshop to set up a 'buddy' list on their mobile phones. This created a sense of community among the students and promoted cooperative learning - a characteristic of social constructivism (Wang, 2008) and a prerequisite for successful DE (Simonson et al., 2012).

Wright et al. (2009) found that students in developing countries often lack technical support due to a dearth of technical expertise in remote areas. Wright et al.'s (2009) suggestion that faculty members must know how to install and maintain computers and 
software, and troubleshoot problems that they and their students may encounter, was adhered to in the ICT module under investigation. To counteract participants', lack of computer knowledge they were guided in setting up their own laptops during their first workshop. Technical assistance was also given to them by an ICT technician during a workshop presented at the UFS. An administrative assistant was also available during office hours to assist students with technical and academic queries.

In addition to comparing the participants' responses to the open-ended items in the two questionnaires, the ICT module can also be evaluated using Jung and Latchem's (2007) DE quality indictors:

$>$ Conform to the standards applying to conventional education: The ACE:SLM programme was approved by the HEQC of the South African Council of Higher Education (CHE, 2005) and is subjected to regular national and institutional quality assurance reviews.

$>$ Fitness for purpose: The purpose of the module is to give school principals and senior management information on the use and management of ICT resources in order to provide ICT leadership at their respective schools, as well as to provide them with insights into the potential and implication of ICT usage for teaching and learning (Bialobrzeska \& Cohen, 2005). Findings from the second questionnaire bear witness to the participants' ability to use ICT proficiently to fulfil their multiple roles as teaching and learning, administrative, academic staff and community leaders at the conclusion of their studies.

> Meeting customers' needs: Research by Harris et al. (2009) found that attitude and motivation are particularly important in ICT studies. It was therefore important to consider the customers' circumstances, needs, learning styles, expectations and motivations when planning and presenting an ICT DE module. Students' expectations and concerns, as conveyed in the first audit survey, as well as practicalities, such as a lack of reliable internet connectivity were used as point of reference for facilitating the module. Rigorous analyses of students' concern, but also their critical reflections convey the message that the ICT module meets their needs.

> Continuous improvement: The facilitator followed an action research approach to her teaching. She spends many hours reflecting, consulting her diary, and watching video clips and photo portfolios to gain insight into her students' needs, successes and failures. The main reason for this research report is to scientifically engage with the students' evaluation. Findings from this study will be used to improve the organisation, support and facilitation of future ICT DE modules.

$>$ Conformity with international standards and requirements: The study guide for the ICT module was developed by acclaimed DE and ICT leaders from the South African Institution of Distance Education, namely Bialobrzeska and Cohen (2005). The study guide bears out their knowledge of up-to-date developments in the fields of ICT and DE.

\section{CONCLUSION}

An ICT module that set out to empower education leaders to become informed and skilled ICT leaders, was envisaged by the facilitator in accord with the social constructivist theory. Insight into the concerns of her students was therefore an important scaffold for unpacking the content of the module in a practical, nonthreatening, yet challenging manner. The first audit survey exposed the education leaders' lack of ICT knowledge and skills, as well as their fear of failure. By creating a sense of community, setting up support structures and innovative learner-centred facilitation, the facilitator attempted to address their concerns. 
This study used two modes of evaluation: Jung and Latchem's (2007) quality indicators for DE and comparison (participants' concerns were compared with matters arising from their reflections at the conclusion of the module). Although no method of evaluation is perfect, it may be concluded that the ICT module succeeded in its aim to empower school leaders to become ICT proficient and that the module adheres to DE quality indicators.

The study highlights the importance of ready access to ICT, technical support, appropriate guidance and support by knowledgeable, innovative and committed facilitators. Furthermore, the creation of a sense of community is imperative for teaching education leaders ICT skills and knowledge. Providers of ICT DE programs should thus attend to issues, such as the availability and reliability of ICT, adequate technical support structures and infrastructure. The role of the facilitator in the success or failure of an ICT DE module cannot be overemphasized. It is therefore recommended that capacity building of ICT facilitators be prioritized. The creation of a sense of community and support by the organization is important in DE. Infrastructure, technical and academic support should be only a phone call, email or text message away. All of these recommendations may have huge cost-implications for universities, students, government, funding organizations and the providers of telecommunication. Yet, these costs should be juxtaposed against the positive outcomes of a well-planned, innovative and inspiring ICT module. Education leaders and potential leaders who were part of this study embraced their multiple roles as ICT leaders and managers in their classes, among their academic and administrative colleagues and in their communities.

\section{BIODATA and CONTACT ADDRESSES of AUTHORS}

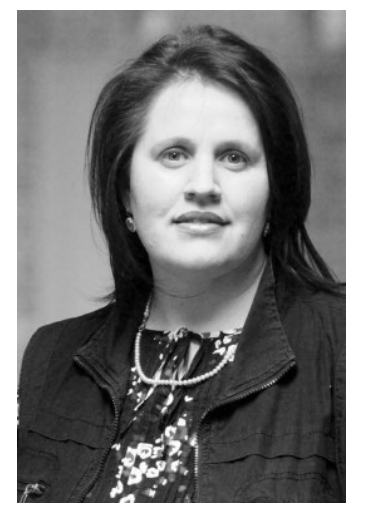

Sarietjie MUSGRAVE is currently the director of Ideas Lab at the School of Open-Distance Learning, University of the Free State, South Africa. She holds a B.Ed.Hons (Cum Laude) in Curriculum Studies (2004) and is currently busy with her MBA. She has been teaching for more than 20 years across the education spectrum, from Early Childhood and special needs education to adult education. She served on the International advisory board for Microsoft Global Education and the New Horizon K-12 report, did research for UNESCO's Institute for information technologies in education (IITE) focusing on ICT in Primary Schools (2013) and served as subject matter expert for the UNESCO ICT Competency Framework for teachers (2011). Her interest areas are digital learning, ICT Competencies of pre-service teachers, teachers and school leaders, educational interfaces, and open and distance learning.

\section{Sarietjie MUSGRAVE}

Open-Distance Learning

University of the Free State, Bloemfontein, South Africa, 9300

Phone: +27515051226

E-mail: musgraves@ufs.ac.za

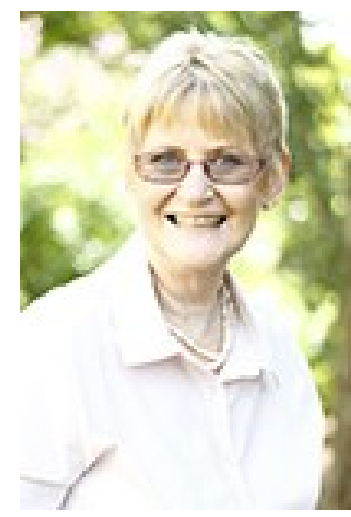

Corene DE WET (emeritus Professor in Comparative Education) is currently a research fellow at the School of Open-Distance Learning, University of the Free State, South Africa. She holds a D.Ed. in Comparative Education (1991) and a Ph.D. in History (1998). She has authored and co-authored more than $\mathbf{9 0}$ articles in South African and international peer reviewed journals, as well as three chapters in books. She is the co-editor of two books. She presented numerous papers at South African and international conferences. Her research focuses firstly on violence, bullying and sexual harassment amongst pupils, secondly on teachers as victims and perpetrators of workplace bullying and violence, and thirdly on open and distance learning. 
Prof. Dr. Corene DE WET

Open-Distance Learning

University of the Free State, Bloemfontein, South Africa, 9300

Phone: +27 515051285

E-mail: dewetnc@ufs.ac.za

\section{REFERENCES}

Afshari, M., Bakar K. A., Luan, W. S., Samah, B. A., \& Fooi, F. S. (2009). Technology and school leadership. Technology, Pedagogy and Education, 18(2), 235-248.

Aluko, R. (2009). The impact of an Advanced Certificate in Education (ACE) program on the professional practice of graduates. International Review of Research in Open and Distance Learning, 10(4), 1-25.

Bialobrzeska, M., \& Cohen, S. (2005). Managing ICTs in South African schools. A guide for school principals. Johannesburg: SAIDE.

Bush, T. (2012). International perspectives on leadership development: making a difference. Professional Development in Education, 38(4), 663-678.

Bush, T., Duku, N., Glover, E., Kiggundu, E., Kola, S., Msila, V., \& Moorosi, P. (2009). External evaluation research report of the Advanced Certificate in Education: School Leadership and Management. Pretoria: DBE.

CHE (Council on Higher Education). (2005). National review of the Master of Education programmes manual. Pretoria: CHE.

Creswell, J. W. (2008). Educational research: Planning, conducting and evaluating qualitative and quantitative research. Upper Saddle River, New Jersey: Pearson.

DHET (Department of Higher Education and Training). (2012). Draft policy framework for the provision of distance education in South African universities. Pretoria: DHET.

Dewey, J. (1933). How we think. New York: Prometheus Books.

Flanagan, L., \& Jacobsen, M. (2003). Technology leadership for the twenty-first century principal. Journal of Educational Administration, 41(2), 124-142.

Hadijthoma-Garstka, C. (2011). The role of the principal's leadership style in implementation of ICT policy. British Journal of Educational Technology, 42(2), 311-326.

Harris, P., Connolly, J., \& Feeney, L. (2009). Blended learning: overview and recommendations for successful implementation. Industrial and Commercial Training, 41(3), 155-163.

Jung, I. \& Latchem, C. (2007). Assuring quality in Asian open and distance learning. Open Learning, 22(3), 235-250.

Keegan, D. (1990). Foundations of distance education. ( $2^{\text {nd }}$ ed.). London: Routledge.

Kundi, G. M., \& Nawaz, A. (2010). From objectivism to social constructivism: The impacts of information and communication technologies (ICTs) on higher education. Journal of Science and Technology Education Research, 1(2), 30-36. 
Mdlongwa, T. (2012). Information and Communication Technology (ICT) as a means of enhancing education in South Africa. Policy Brief, Africa Institute of South Africa, 80, 1-7.

Naicker, V. (2013). Understanding the role of principals and the use of computers in secondary schools. South African Journal of Higher Education, 27(4), 966-984.

Ngugi, C. N. (2011). OER in Africa's higher education institutions. Distance Education, 32(2), 277-287.

Nieuwenhuis, J. (2007). Analysing qualitative data. In K. Maree (Ed.), First steps in research (pp. 91-122). Pretoria: Van Schaik.

Rogers, C. (2002). Defining reflection: Another look at John Dewey and reflective thinking. Teachers College Record, 104(4), 842-866.

Sampson, N. (2003). Meeting the needs of distance learners. Language Learning \& Technology, 7(3), 103-118.

Sikwibele, A. L., \& Mungoo, J. K. (2009). Distance learning and teacher education in Botswana: opportunities and challenges. International Review of Research in Open and Distance Learning, 10(4), 1-16.

Simonson, M., Smaldino, S., Albright, M., \& Zvacek, S. (2012). Teaching and learning at a distance. Foundations of Distance Education. ( $5^{\text {th }}$ ed.). Boston: Pearson.

Wang, Q. (2008). A generic model for guiding the integration of ICT into teaching and learning. Innovations in Education and Teaching International, 45(4), 411-419.

Wright, C. R., Dhanarajan, G., \& Reju, S. A. (2009). Recurring issues encountered by distance educators in developing and emerging nations. International Review of Research in Open and Distance Learning, 10(4), 1-25. 